\title{
VIOLENCIA, EDUCACION Y DERECHOS HUMANOS
}

\section{Por: Darío Betancourt F.}

Aun cuando la violencia no es de origen biológico, acompaña al hombre desde la más remota antigüedad cuando la división del trabajo y los remanentes del producido social, dieron pie a una apropiación desigual del mismo, situándose en el plano económico, social, político y cultural.

En este sentido la violencia existe, se da, se presenta como expresión de la dominación de clase, por parte de las élites que controlan el aparato de Estado.

Podríamos definir la violencia como los comportamientos destinados a causar perjuicios físicos a personas, o daños a cosas; empleo efectivo de la amenaza y de la fuerza para obligar a otros a hacer lo que no harían en condiciones normales; el hecho producto de la fuerza bruta, de la compulsión, de la imposición de unos sobre otros, sea por los gestos, por la voz, por la mirada o por el hecho mismo, que puede ser un golpe o el uso de instrumentos materiales para herir, para destruir al otro, etc., la violencia puede presentarse en formas más sutiles, más indirectas, pero con la misma finalidad, llegar al hecho último que facilite la destrucción, la muerte, la desaparición, el perjuicio físico, mental o moral, del otro. ${ }^{1}$

No obstante lo anterior, siguen siendo vagas e incomprensibles las situaciones históricas y sociales que la producen.

"Nos es muy difícil comprender la violencia como fenómeno histórico o social, como pone de manifiesto la extraordinaria devaluación de téminos como agresión en la jerga psicosociologica popular, o genocidio en la política”.2

La ola de violencia en una época como la actual, en la que casi todas las naciones se ven afectadas por este fenómenoo, es harto compleja, y más aun cuando los esquemas de análisis siguen apegados a las interpretaciones liberales

\footnotetext{
* Profesor: Darío Betancourt E.

${ }^{1}$ Para profundizar sobre la violencia, ver: HOBSBAWM. E. Las reglas de la violencia, Ariel, Barcelona, 1978.

BARREIRO, 3. Violencia y política en América Latina, Siglo Veintiuno, México, 1971.

PEREYRA, O. Política y violencia. Fondo de Cultura, México, 1974.

SOREL, G. Reflexiones sobre la violencia. Carlos Valencia Editores, Bogotá, 1976.

CLAUSEWITZ, K. De la Guerra. Labor, Barcelona, 1982.

GIRARD, R. La Violencia y lo Sagrado. Universidad Centra, Caracas, 1975.

ENGELS, F. Théorie de la violence. Inédit, París, 1972. WALTER, B. Para una crítica de la violencia y otros ensayos. Taurus, Madrid, 1991.

WOLFGANG, M. Y FERRACUTT, F. La subcultura de la violencia. Fondo de Cultura, Méxiø, 1971. QUINNEY, R. Clases, Estado y Delincuencia. Fondo de Cultura, México, 1985.

ZULETA, E. Sobre la guerra. En: Elogio de la Dificultad y otros ensayos. Fundación Estanislao,

Bogotá,

1994.

${ }^{2}$ HOBSBAWM. Op. Oit. P. 295 
que dan por cierta una dicotomía muy discutible entre violencia o fuerza física (con características malévolas, bárbaras, primitivas y retrogadas), y la no violencia, 0 fuerza moral (buena, digna e hija de progreso) ${ }^{3}$

Se tiende pues, con estos reduccionismos, a soslayar precisamente que la violencia, como fenómeno histórico y social, no sólo existe bajo múltiples formas y manifestaciones, según las contradicciones de la sociedad en que se produce sino que la violencia, atraviesa permanentemente toda la estructura social.

En Colombia históricam ente no encontramos la categoría de ciudadano, y lo que muchos interpretan como debilidad del estado es, en últimas, la expresión de una sociedad civil débil y sin organización que, al carecer de ciudadanos plenos, solo identifica a una serie de habitantes dispersos, reconocidos y representados en su heterogeneidad como elementos naturales, una sociedad civil en que no encontramos elementos de cohesión sino de exclusión, que siempre ha tendido a resolverse mediante la sujeción o la destrucción del otro. Sobre esta base se ha construido la llamada democracia Colombiana, más tradicional que modema, con múltiples formas de dominación privada de lo social y lo público.

Sin tradición democrática, la sociedad colombiana no puede ser fácilmente entendida dentro de la oposición clásica de Democracia o Dictadura, Orden o Violencia, y tal vez sea mejor considerarla, para entender nuestra realidad y el papel que en ella ha jugado la violencia, como una sociedad que se caracteriza porque en ella se han venido dando simultáneamente la Democracia y la Dictadura.

La dualidad Democracia y Dictadura tiene que ver con la dominación hegemónica de una oligarquía liberal-conservadora excluyente que controla el Estado. Para los colombianos, el Estado no es una institución que resuelve los conflictos y garantiza el orden; por el contrario, está inscrito permanentemente en el conflicto $y$, aun cuando detenta oficialmente la función de imponer el orden, su orden es la violencia hegemónica. Para los colombianos no existe el Estado como Estado Nacional, sino como Estado partidista; en este sentido no es supraconflictual, sino que es un elemento del conflicto (véase los casos de la policía y de la iglesia en la violencia del cincuenta a manera de ejemplo).

Hasta el Frente Nacional, e incluso hasta la década del setenta, la lucha partidista en Colombia se caracterizó por la combinación del binomio Violencia y Fraude; todos los cambios de hegemonía se caracterizaron por el despliegue de acciones violentas, combinadas con la lucha por el dominio de los puestos públicos y el fraude electoral (las coyunturas más traumáticas fueron las de 1931, 1946 y 1949).

\footnotetext{
${ }^{3}$ HOBDBSWM. IDEM. Pp.295-296 
Los diferentes grados de violencia suponen des de luego rasgos cualitativos y cuantitativos diferenciadores de la misma: en nuestro país el conflicto agrario y la acción política, dos constantes generadoras de violencia, ilustran sobre lo anterior.

En cuanto al primero, si bien es cierto que prácticamente todos los movimientos campesinos generan manifestaciones de fuerza física, no lo es menos que unos son más parcos en el derramamiento de sangre que otros. Tales son los casos del conflicto agrario de la década del veinte, com parativam ente menos violento" que el conflicto agrario vivido en algunas regiones en los marcos de la violencia de los cincuenta, y a la vez, los dos anteriores cualitativa y cuantitativamente menos violentos que la lucha por la tierra que se ha librado por debajo de las más atroces matanzas de Córdoba, Urabá, Meta, Santander, Cundinamarca, Boyacá y Cesar, en los últimos años.

En cuanto a la violencia política hay muchos más elementos para entender sus diferentes grados de intensidad y complejidad: Es indudable, que en el marco de las guerras civiles fue mucho más magnánime el establecimiento en el tratamiento que le dio a las fuerzas rebeldes cuando éstas eran fracciones de uno u otro partido tradicional, en relación con el que correspondió a los campesinos en amas que no se sometieron a los designios excluyentes del Frente Nacional, ya que éstos fueron cazados como "vulgares" malhechores" y "bandidos". Ahora bien, fue muy diferente el manejo implementado por el Estado para reprimir el movimiento guerrillero, surgidlo en la década de los setenta sobre los escombros de la violencia partidista, ya que siempre se le negó el carácter de fuerza insurgente y se le calificó como "delincuencia común" o "asociación para delinquir". Muy contrario fue el tratamiento

dado al conflicto social y político de los ochentas: por un lacio, pareció ganar fuerza la tesis según la cual la guerrilla era una fuerza política con la que había que sen tarse a dialogar, por otro, bajo el esquema de la "guerra sucia", sistemáticamente fueron eliminados los opositores al régimen. Así, mientras unos hablaban de diálogo, otros nuevamente calificaban a las fuerzas insurgentes como simples "bandidos", "malhechores" y "terroristas

Es aquí donde se hace necesario) iniciar la primera fase de una labor educativa y pedagógica, si tenemos en cuenta que uno de los más graves problemas que presenta la actual coyuntura violenta es la confusión. Hablar a secas de terrorismo para designar actuaciones del narcotráfico, de la delincuencia común, de la guerrilla, y de los sicarios.,corno lo hacen sectores del gobierno y algunos medios cte comunicación, es sin lugar a dudas una manera "velada" de justificar la guerra sucia y la violencia de Estado, máxime si se trata de funcionarios del gobierno y algunos sectores que solamente alzan su voz de alama frente a las acciones de los movimientos sociales, pero callan frente a otras manifestaciones de violencia, por ejemplo, a las generadas por la estructura económica o por agentes del Estado. 


\section{EDUCACION Y VIOLENCIA}

El primer paso que debemos dar desde la escuela y la universidad es, necesariamente, el franco y abierto reconocimiento de que vivimos en una sociedad carcomida en todos sus estamentos por la violencia.

La sociedad colombiana ha pasado por múltiples situaciones violentas, con manifestaciones económicas, sociales, políticas y culturales; estudiar comprender y evaluar estas situaciones de violencia debe ser, sin lugar a dudas, prioritario en el avance hacia la "regulación", "contestación", "manejo" y "eliminación" de los hechos violentos, generalmente causados y desbordados ver las situaciones de violencia, expresadas en una estructura social y económica que niega a la mayoría de sus miembros las necesidades más elementales.

Como la violencia existe, se da, se impone la tarea de as egurar los mecanismos sociales que garanticen dignas condiciones de vida, para que así los hechos violentos no se desencadenen hasta afectar el clima social que sustituye a la concordia y a la fraternidad.

No obstante, la violencia seguramente seguirá "existiendo", pues si en la relación opresor-oprimido, la violencia supone el sometimiento del segundo por el primero, en la relación de seres humanos realmente iguales, la violencia supone el ejercicio de una negatividad dirigida no para someter a otro, sino para someternos nosotros mismos a las reglas de la vida social amónica'.

Es necesario, pues, fomentar una educación para la concordancia, la paz y la armonía, una educación que respete la diferencia, que tenga en cuenta al otro aunque piense distinto. Pero es una utopía, es demagógico, pretender que a tal situación se llega mediante el discurso "moralista" del maestro en la escuela, de los medios de comunicación, o de las acciones de grupos sociales altruistas; este proceso pedagógico no avanza si la sociedad misma no se transforma, si el Estado y las instituciones no se democratizan, pues como se ha mostrado ya, es la estructura económica y social la que desencadena las situaciones de violencia que de una u otra manera conducen a los hechos violentos.

El derecho a la vida pasa necesariamente por el derecho al trabajo, a la educación, a la salud, a la vivienda, a la recreación, a la libertad de, etc., de todos los colombianos. Si el estado no garantiza a sus asociados éstos derechos, cómo evitar el desbordamiento de los hechos violentos?

Creemos que es imperativo asumir una labor seria, sostenida y franca, para enseñar a nuestros alumnos que los hechos violentos pueden "manejarse", "reglamentarse' y "normatizarse", pues aún las sociedades históricamente más violentas han logrado el respeto de ciertas "reglas". El peligro más grave para una sociedad es la pérdida de los mecanismos sociales que controlan la fuerza física,

\footnotetext{
${ }^{4}$ BARREIRO, J Violencia y política en América Latina, siglo veintiuno. México. 1971.
} 
principalmente en el momento en que nuevas formas de violencia social atraviesan por una fase as cendente.

Como bien lo ha señalado Hobsbawm ${ }^{5}$, el crecimiento de las defensas civiles, la seguridad privada, el incremento de la policía y otras fuerzas de seguridad, que se han venido acostumbrando al uso cotidiano de la violencia física, des de la simple detención de un ciudadano hasta el uso cada vez más generalizado de la desaparición y la tortura, son procesos que se ven dinamizados por el pedido de sectores sociales que reclaman la aplicación indiscriminada de la fuerza.

\section{APARATO ESCOLAR YVIOLENCIA}

No nos llamemos a engaño, la escuela ha venido siendo utilizada, desde el triunfo de la burguesía sobre la aristocracia feudal, como herramienta ideológica, política y cultural, para justificar los privilegios de unos pocos en detrimento de los intereses de las mayorías.

Los rituales y dogmas inventados por la escuela han buscado siempre hacer aceptable para el niño y para el joven las contradicciones de la sociedad presentándolas a través del proceso lento y persistente de la socialización de su personalidad para que tenga "éxito en la vida, en la sociedad de consumo, o en el peor de los casos (que es $\mathrm{e}^{1}$ más generalizado), para que se resigne "democráticamente" a los designios y mandatos de la sociedad en que se desenvuelve.

La violencia en nuestro sistema educativo está representada por la negación que hay en los métodos pedagógicos de los intentos de concientización y por la finalidad de interiorizar la conciencia de los poderosos; recordemos las airadas protestas de El Tiempo y Germán Arciniegas frente a aquellos textos de historia para niños que han mostrado otra cara de los procesos sociales y que han desmitificado a algunos "héroes", en contra de ciertos grupos sociales que aún creen que ellos y sólo ellos son los llamados a "escribir la historia" y a construir las versiones de patria y nacionalidad para las escuelas y colegios. ${ }^{6}$

La actual estructura del aparato educativo colombiano es una fuente generadora de violencia. Expandido en los marcos de la Violencia de los años cincuentas, despersonalizó, rompió tradiciones culturales, estandarizó y cosificó al estudiantado otrora citadino y comunitario. No pueden perderse de vista las triples jornadas, sin recreos, sin juegos, sin socialización, a las que se sumó un maes tro "domesticado" como simple "administrador de currículo", en los marcos de la Tecnología Educativa que dejó en manos de los medios masivos de comunicación el afianzamiento de los valores cívicos y culturales de la juventud, valores que

\footnotetext{
${ }^{5}$ Idem. Pp 298-303

6 Recuérdese la polémica por los textos de historia de Editorial Estudio 1985-1986, ampliamente difundida por la prensa.
} 
generalmente han sido reemplazados por las tentaciones del consumismo extranjerizante e individualista de los tenis, la camiseta, la moto y el enriquecimiento fácil, todos ellos profundos generadores de violencia.

No es gratuito que el actual sicariato y las pandillas se sostengan con jóvenes que fluctúan entre los 15 y los 25 años, muchos de los cuales ingresaron al mismo, en búsqueda de recursos para comprar ropa de marca, un carro, o hacerse un plante para ser "alguien en la vida", motivados por el desempleo, la falta de oportunidades y la desesperanza generalizada que ha invadido a una juventud a la que tanto la sociedad como el Estado no le ofrecen sino la imitación de las imágenes de la "alta" vida social, del cine y de la televisión: vida de enriquecimientos fáciles, de crímenes, de vengadores y exterminadores que limpian ciudades y poblados.

Dos realidades bien opuestas se ofrecen cotidianamente a nuestros muchachos: mientras una amplia mayoría de colombianos subsisten con el subempleo y otras fuentes informales de trabajo, o se debate bajo los aletazos de la miseria absoluta, otros pocos, los que siempre han tenido, logran mediante la manipulación y el robo disimulado, grandes fortunas.

¿Cuál derecho a la vida?, ¿cuáles derechos humanos? Estas parecen ser dos de las más significativas preguntas para responder si la vida física de los que han sido eliminados, pasa por el vivir cotidiano no solo de ellos, sino de miles de colombianos que no tienen comida, techo, educación, expresión, capacidad de hacer política, en una palabra DEMOCRACIA. Los Derechos Humanos no solo deben entenderse desde el ángulo político, sino, también, como el vivir con dignidad, con igualdad de oportunidades y derechos, como lo aspira y lo merece el grueso de los habitantes de nuestro país.

Los maestros y estudiantes que convivimos en la escuela, el colegio y la universidad tenemos una misión urgente por cumplir: encontrarnos con la sociedad toda, estudiar, entender y problematizar sus dinámicas, a fin de romper la falsa neutralidad, la falsa imparcialidad del aula de clase, para de esta manera confrontar nuestros saberes con la realidad misma, para desmitificar los textos y las teorías, para reivindicar al lado de la ciencia a la "magia", la "música", el "sentim iento" y la "nos talgia", como profundas fuentes tanto de saber como de vida ylibertad. ${ }^{8}$

\footnotetext{
${ }^{7}$ Para estudiar las violaciones a los Derechos Humanos ver: AMERICAS WATCH. La violencia continúa. Asesinatos políticos y reforma institucional en Colombia. Tercer Mundo- Lepri, Bogotá, 1992.

AMERICAS WATCH. Estado de Guerra. Violencia política y contrainsurgencia en Colombia. Tercer Mundo. Lepri, Bogotá, 1994.

MEDINA, O. Y TELLEZ, M. La violencia Para institucional, Paramilitar y Para policial en Colombia. Rodríguez Quito Editores, Bogotá, 1994.

${ }^{8}$ Para pensar y valorar la cultura popular y otras fuentes de conocimiento, puede verse: GARCIA CANCLINI, N. Culturas híbridas. Estrategias para entrar y salirde la modernidad. Grijalbo, México, 1990.
} 
La lucha por la vida, por la democracia y los Derechos Humanos, pasa no solo por la lucha social, sino por reconocer que la educación debe ser una gran dinamizadora de la democracia y de la cultura, una gran fuerza cultural y moral que contribuya al replanteamiento del actual proyecto social.

Educar para la vida y la democracia pasa por la creación de condiciones en el medio social tendientes a que los hombres puedan continuar autoformándose para ser sujetos de desarrollo social, además de sujetos de desarrollo personal. La educación debe dejar atrás las Técnicas Escolares que habrán de transformarse en métodos de formación fundamental e integral (actividades cívicas, vocacionales, sociales, culturales, etc.). La educación debe facilitar al individuo una participación política integral, en la que deben estar presentes un conocimiento profundo de la estructura económica y socio-cultural de la sociedad; solo así "manejaremos" los Hechos Violentos. 